10 April 2016

\title{
Pragmatic Reasons for Belief ${ }^{1}$
}

[Penultimate Draft]

\section{O. INTRODUCTION}

Outside of sceptical moments, we in general take it that the world has a particular shape and character. We call our committed impressions of its shape and character 'beliefs', and we use them to navigate a course through it.

Insofar as we rely on our beliefs to keep us from walking into walls or to avoid burning the toast, it is generally advantageous to us for them to be true. The convergence of truth and advantage with respect to particular beliefs is the rule rather than the exception in ordinary circumstances. $^{2}$

Yet it is not difficult to see that for particular beliefs in some circumstances a wedge may be driven between truth and advantageousness. Cases range from the exotic - with diabolical forces conspiring to punish a hapless victim for believing the truth - to the the mundane - with excessive optimism increasing one's chances of success at some tasks. With that wedge comes the prospect of competing norms for particular beliefs.

In the background of many philosophical writings rests the assumption that the appearance of competing norms is mere appearance. Whatever one may say about the benefits attached to believing something, the only considerations that genuinely count in favour of having a belief are

\footnotetext{
${ }^{1}$ This chapter arises out of many years of work on evidentialism and pragmatic reasons for belief. The chapter has most directly benefited from Miriam McCormick's generous comments equally generous comments and advice from Daniel Star. More broadly, this chapter reflects discussions or correspondence with many people over many years with interlocutors too numerous to name.

${ }^{2}$ This is not only the case for empirical beliefs, but also mathematical and perhaps even moral beliefs. For the latter, see Reisner and Van Weeldon (2015).
} 
those arising from its truth.

Writers who make this assumption, what I shall call the 'truth norm', ${ }^{3}$ explicit, typically do so in one of two ways. One is in the form of what I shall call the 'truth-correctness principle' and the other are in various versions of what I shall call 'non-ecumenical evidentialism'. The truthcorrectness principle is demanding. It says that the sole norm of belief is truth; one ought to believe $p$ when $p$ is true and not believe $p$ when $p$ is false. The truth-correctness principle is binary in this way; there is no more reason to believe a false belief with more evidential support than there is to believe a false belief with less evidential support.

In contrast, non-ecumenical evidentialism holds that the principal expression of the truth norm comes in the form of normative reasons that are, or are given by, the evidence. If the evidence is strong enough for a false belief, then it can be the case that one ought to believe it. What makes non-ecumenical evidentialism be non-ecumenical is that, like the truth-correctness principle, it excludes that possibility that there are normative reasons for belief that arise from considerations other than generally alethic ones. I shall refer to the family of views that hold that all normative reasons for belief arise from truth-related considerations as 'alethicism'.

While some version of the truth norm is quite widely accepted in philosophical writings, it is not entirely uncontroversial. Some authors think that various non-alethic or non-epistemic considerations provide at least some of our normative reasons for belief. These authors are generally called 'pragmatists', and the kind of reasons that they accept, and that are rejected by those who adhere to the truth norm, are called 'pragmatic reasons for belief'.4 This kind of pragmatism is distinct from the wider American philosophical movement of the same name,

\footnotetext{
${ }^{3}$ My use of 'truth norm' deviates from some uses of the expression to mean what I call the 'truth-correctness principle' in this chapter.

${ }^{4}$ Stephen Stich (1990) began the contemporary discussion of pragmatism about reasons for belief. His work has had a more marginal influence on current debates than might be expected, one suspects in part because he bases his main argument on controversial claims about the nature of reference and truth.
} 
which in some forms had more radical aspirations to revise our fundamental understanding of truth and of knowledge. ${ }^{5}$ In this context, pragmatic reasons are those that arise from moral, prudential, and perhaps aesthetic considerations. ${ }^{6}$

The aim of this chapter is to give an overview of the current debate about pragmatic reasons for belief. The dialectic of this debate treats one version of the truth norm, non-ecumenical evidentialism, as the implicit default position. Consequently, much of the discussion about pragmatic reasons for belief has occurred in the context of defending, or trying to undermine, nonecumenical evidentialism. The organisation of this chapter reflects the structure of the debate itself, and consequently despite being about pragmatic reasons for belief, much of the discussion is focused on the arguments for non-ecumenical evidentialism. $\mathbb{S} 1$ contains a brief discussion of why non-ecumenical evidentialism is generally seen as the default view, with particular attention paid to its advantages over the truth-correctness principle. $\$ 2$ discusses what may be termed 'old style' arguments for non-ecumenical evidentialism and why those arguments have been rejected. $\mathbb{S}_{3}$ discusses what may be termed 'new style' argument for non-ecumenical evidentialism and their relation to what I shall call 'quasi-analytic evidentialism'. $\$ 4$ explains why 'new style' arguments for non-ecumenical evidentialism are unsuccessful. $\mathbb{S} 5$ presents the positive arguments for pragmatic reasons for belief. $\$ 66$ concludes by considering the degree to which accepting that there are any pragmatic reasons for belief pushes us towards the view that all non-derivative reasons for belief are pragmatic.

\footnotetext{
${ }^{5}$ Skorupski (2011) thinks that traditional pragmatism cannot be escaped, if we accept that there are pragmatic reasons for belief. His view is not shared by contemporary defenders of the view that there are pragmatic reasons for belief. ${ }^{6}$ This list need not be exhaustive.
} 
1. The truth NORM, THE TRUTH-CORRECTNESS PRINCIPLE, AND NON-ECUMENICAL EVIDENTIALISM

Discussions about the nature of belief commonly involve platitudes such as, 'belief aims at truth' or 'to believe $p$ is to believe $p$ true'. ${ }^{7}$ The theorisations of these platitudes are both diverse and debated, in part because it is difficult to spell out the pre-theoretical intuition that motivates them with much precision.

A thin, but perhaps adequate, way of understanding the pre-theoretical intuition that underpins the platitudes is that beliefs are characterised by two important features. One is that the output role of belief in our cognitive architecture is to represent the world accurately. ${ }^{8}$ The other is that within our cognitive economy, individual beliefs typically are formed or change in response to what the believers take to be the case.

Philosophers who accept a version of the truth norm rely in one way or another on this pretheoretical intuition, or a theorised version of it, to explain why the truth norm alone - at least as they understand the truth norm - provides normative reasons for belief. Within the literature on reasons for belief, the truth norm is most commonly understood as being expressed by a version of non-ecumenical evidentialism. Consequently, $\mathbb{S}_{2}, \mathbb{S}_{3}$, and $\mathbb{S}_{4}$ of this chapter focus on nonecumenical evidentialism and its discontents. In the remainder of this section, the discussion is concentrated on why the truth-correctness principle is in comparative disfavour; further discussion of non-ecumenical evidentialism is confined to some taxonomic remarks.

\section{The Truth-Correctness Principle}

The truth-correctness principle is a normative version of the platitude that to believe $p$ is to

\footnotetext{
${ }^{7}$ For a particularly helpful discussion of how these platitudes might be fruitfully cashed out, see Wedgwood (2003).

${ }^{8}$ It is difficult to capture this thought in terms acceptable to dispositionalists about belief. See Barcan Marcus (1990). I shall not try to do so here.
} 
believe $p$ true. Put in normative form, it is correct to believe $p$ if and only if $p$ is true. This account of the truth norm gains at least its prima facie appeal from our judgements about the correctness of beliefs. Supposing we come know that $p$ is false, if we are asked whether an individual's belief that $p$ is correct, many of us, at least, would be inclined to say that it is not. It is difficult to hear a question about the correctness of a belief as something other than a question about its truth.

To leverage the intuitive judgement that correct beliefs are true beliefs into the truthcorrectness principle, an appropriate subset of four argumentative tasks would need to be discharged:

1. To show that correctness is itself a robust normative property, or that it is a source of a robust normative property like being a reason.

2. To show that if correctness is only a source of a robust normative property like being a reason, the kind of reason it provides is a complete reason (or an ought) for what is correct to believe.

3. To show that if correctness itself is a robust normative property, it is tantamount to being a complete reason or an ought.

4. To show that if correctness itself is tantamount to being a complete reason or an ought, or that it provides a complete reason or an ought, there are further pro tanto reasons for belief of a different kind.

1) is the requirement that the property of correctness be understood as a normative property in a way that connects it with reasons or oughts. 2) treats correctness as a source of reasons, rather than itself being a kind of reason. The possibility that there are other sources, or kinds, of reasons for belief must be ruled out. 3) requires correctness, if it is tantamount to being a reason or an ought, to be normatively complete and not merely a pro tanto reason. 4) ensures that correctness alone provides 
reasons for belief. To derive the truth-correctness principle from truth being the correctness criterion for belief, it is necessary to defend either 1), 2) and 4), or 1), 3), and 4 ). ${ }^{9}$ The outlined tasks fall into two categories. One is to bridge correctness and being a reason. The other is to show that correctness reasons are complete reasons or oughts. This makes the truth-correctness principle stronger than non-ecumenical evidentialism.

According to the truth-correctness principle, for any particular belief $p$, there is precisely one reason to believe it, namely that it is true, or precisely one reason not to believe it, namely that it is false. There are no reasons to suspend judgement. ${ }^{10}$ Because the reasons are complete reasons or oughts, not only is there never any positive reason to suspend judgement, but the suspension of judgement is never permissible.

The binary character of reasons for belief entailed by the truth-correctness principle not only entails a revisionary view about the permissibility of suspending judgement in some circumstances, but it also can privilege facts that are inaccessible to the agent over and above those that are accessible to him. An example, localised alien occasionalism (LAO), makes this clear.

We may imagine that a farmer in Saskatchewan believes that his wheat crop in each of his fields is growing at a such-and-such a rate with such-and-such expected yield, on account of the combination of soil, climate, and care is thus and so. While this belief is true of most of his crop, one particular field has been targeted by aliens who accept the truth-norm, and who mischievously desire to put the farmer out of conformity with his reasons. To achieve this, they use technology undetectable to humans that acts on the the individual molecules in the affected wheat plants, adding and removing them as necessary, so that the wheat will appear to be growing normally.

\footnotetext{
${ }^{9}$ At the time of this writing, there has been no serious effort to discharge these argumentative tasks. For present purposes, this lacuna in the literature need not concern us. The most extensive discussion of the notion of a correctness reason appears in Danielsson and Olson (2007). Nonetheless, that correctness provides reasons serves as a premiss rather than a conclusion in their arguments.

${ }^{10}$ Vagueness may merit the suspension of judgement, but appropriately enough, it is not clearly so.
} 
Their actions leave no trace, and the alien-affected wheat will appear the same as ordinary wheat, when put under any degree of scrutiny by human scientists.

The truth-correctness principle rejects that view that the farmer believes what he ought to believe, by believing his agricultural practices and the environment are causally responsible for the growth rate of the wheat in the field affected by the alien occasionalists. On the other hand he would believe what he ought to believe, were he, unprompted by any evidence, to believe that the wheat grew as it did due to the presence of aliens using undetectable technology to micromanage the cellular changes in the wheat in one of his fields, even though all the facts accessible to the farmer suggest otherwise. Some readers may find a principle that issues in these judgements about LAO odd.

If the judgements seem, or are, odd, it is likely because a requirement to believe what is true can be radically disconnected from information available to us. Explanations of why this radical disconnection is in fact problematic vary. ${ }^{11}$ At minimum, what we ought to believe depends on facts that are epistemically inaccessible to us, then it at least seems that we would need a rather extreme kind of epistemic luck in many circumstances not just to believe what we ought to believe, but what there is any reason to believe at all. ${ }^{12}$

\section{Non-Ecumenical Evidentialism}

Non-ecumenical evidentialism takes up the platitudes expressed by the truth norm in way that is, or is at least intended to be, more consistent with the idea that normative reasons for belief can also play a role as psychological reasons on the basis of which we form our beliefs. ${ }^{13}$ The pre-

\footnotetext{
${ }^{11}$ A detailed discussion of these and other concerns about the truth-correctness principle and its requirements may be found in Gibbons (2013), especially ch. 4, and McCormick (2015), especially ch. 3.

${ }^{12}$ This problem, and related concerns, are not unique to the truth-correctness principle. See Mitova (forthcoming), especially ch. 2, for a careful discussion of related problems for externalist accounts of evidence.

${ }^{13}$ The idea that normative reasons, for action and belief, should be able to serve as the reasons for which we believe
} 
theoretical intuition is that because the truth itself is often epistemically inaccessible, we must rely on considerations that point to what is true and what is not. Those considerations are the evidence for the contents of a belief, or for a proposition more generally.

Evidence could play a number of different roles within a theory of reasons for belief. What distinguishes non-ecumenical evidentialism as being non-ecumenical, is that it does not allow that there are any normative reasons for belief that are not connected to the truth of the contents of the belief for which they are reasons. It is an alethecist view. Ecumenical forms of evidentialism allow that there are both alethic and other kinds of reasons for belief, for example pragmatic reasons for belief.

Non-ecumenical evidentialism itself comes in two varieties, strict and slack. Strict normative non-ecumenical evidentialism is the view that all normative reasons for belief are considerations that count as evidence for the contents of the beliefs for which they are reasons. Slack normative non-ecumenical evidentialism allows that there may be other truth related reasons that are not evidential. Typical examples of the latter include the kinds of reasons one has to believe logical and mathematical truths, as well reasons for self-justifying beliefs (e.g. the belief that I have at least one belief).

It is possible to have ecumenical forms of both strict and slack normative evidentialism. As a matter of terminology, 'strict normative evidentialism' and 'evidentialism' in the literature are both used to denote non-ecumenical varieties of evidentialism. ${ }^{14}$ I shall follow, and amplify, common practice in the rest of the paper. Unless otherwise noted, 'evidentialism' refers to strict nonecumenical normative evidentialism. Strict evidentialists must either shoehorn reasons for the

something has a long history in the reasons literature. See Dancy (2000), Kiesewetter (forthcoming), Mitova (ibid.), and Williams (1981).

${ }^{14}$ Evidentialists are not always precise about formulating the view that they are defending. Skorupski (2011) is an exception. It is generally clear from context, however, that the view being defended, and often assumed, in the literature is strict non-ecumenical evidentialism. 
kinds of beliefs just mentioned into their theory of evidential reasons or claim that there are no reasons for beliefs like those.

Early formulations of what it is to be an evidential reason for belief sometimes built in substantive views about evidence. One view is suggested by Gilbert Harman:

Fact $f$ is an evidential reason for agent $A$ to believe $p$ just in case the conditional probability of $p$ given $f$ is higher than the conditional probability of $p$ given not $f .{ }^{15}$

There is no particular need to be this specific. ${ }^{16}$ A generic schema for evidential reasons for belief can be given:

Fact $f$ is an evidential reason for agent $A$ to believe $p$, just in case $f$ is evidence for $p$.

The schema may be elaborated in various ways, for example to note the strength of the reason or the degree to which $f$ is evidence for $p$. Time and circumstance indices may also be added. For ease of explication, I shall suppress nuances of those sorts. ${ }^{17}$

The generic schema allows for the possibility that one could defend evidentialism without defending a specific account of evidence. Use of a generic schema like this is at present more the rule than the exception. If there is a single substantive constraint that is widely assumed, it is that there can be misleading total evidence, and consequently it is sometimes the case that one ought to

\footnotetext{
${ }^{15}$ Harman (1999). Harman calls these reasons 'epistemic reasons' to contrast them with non-epistemic reasons. I have changed Harman's formulation enough that it seems incorrect to attribute it as a quote. I have done so to make it more consistent with other reasons formulae in this chapter. The essential content nonetheless strikes me being much the same as that in his original formulation.

${ }^{16}$ And there are good reasons for not adopting the Harman formulation. See Reisner (2009) for more discussion.

${ }^{17}$ Skorupski offers a carefully worked out reasons schema in Skorupski (2011).
} 
believe some falsehoods.

\section{Guidinginess}

Settling the dispute amongst philosophers who adhere to the truth-correctness principle and those who defend evidentialism is outwith the scope of this chapter. However, claims about guidingness merit cursory scrutiny, as similar considerations may bear on pragmatic reasons for belief.

It is tempting to think that evidentialism avoids the concerns about guidingness that were raised for the truth-correctness principle, but it is not clearly so. Much depends on how externalist one's account of evidence is. If evidential reasons for belief parallel in structure some externalist accounts of reasons for action, then they are not always clearly better with respect to guidingness than are reasons arising from the truth-correctness principle.

Strong forms of externalism about practical reasons hold that one's reasons are given by the facts, not just those facts that are epistemically accessible. ${ }^{18}$ According to them, what we ought to do may depend on facts that we cannot know about. Externalists about evidence are liable to defend views on which at least some of the evidence is not epistemically accessible. In such cases, there will be a failure of guidingness in whatever sense guidingness also fails for the truthcorrectness norm.

Evidentialists, ecumenical and non-ecumenical alike, are sensitive to this worry, as are pragmatists. Strategies vary, but all involve putting some kind of accessibility constraint on which external pieces of evidence can count as reasons for belief. ${ }^{19}$ It remains an interesting and open

\footnotetext{
${ }^{18}$ Dancy (2000), Parfit (2001, 2010), and Skorupski (2011) offer this kind of externalist account. Dancy is criticised in Mitova (forthcoming).

${ }^{19}$ Dancy (ibid.), who may be classified as an ecumenical evidentialist, and Skorupski (ibid.), who is a non-ecumenical evidentialist, both introduce restrictions on what evidence can count as a reason for belief for a particular agent. Evidentialists could also make use of views about evidence that restrict which facts count as evidence at all for a
} 
question as to how well motivated the addition of accessibility restrictions are for theoretical reasons, when they do not apply to practical reasons. I shall set the matter aside, but a satisfactory account of either evidence or of evidential reasons for belief is required to ensure that evidentialism is better off than the truth-correctness principle with respect guidingness.

\section{OUGHT IMPLIES CAN: THE OLD STYLE OF ARGUMENT FOR EVIDENTIALISM}

Prior to the middle of the last decade, such arguments as there were for evidentialism relied on two premisses: that ought, and therefore being a reason, implies can and that doxastic involuntarism is a conceptual truth..$^{20}$

Both premisses may be challenged, but the old style argument is unsuccessful, even if they are granted. The argument proceeds as follows. We assume direct doxastic involuntarism, and we assume that our beliefs are formed and maintained in response to what we take to be evidence. ${ }^{21}$ We then observe that there is a restriction on what there can be reason to believe on the basis that we can only believe those things for which we take there to be evidence. Taken together, this is supposed to entail evidentialism.

The trouble with this argument is that there is no non-gerrymandered sense of 'can' on which it is valid. ${ }^{22}$ The relevant sense of 'can' is not 'can will', as one might assume for a parallel principle for reasons for action. This is because the argument assumes that we cannot will our beliefs, so 'can will' would yield no reasons for belief at all, evidential or otherwise.

If we take 'can' as 'psychologically can', involuntarism becomes a problem once again. There is no direct freedom in belief according to the involuntarist premiss. Thus, the only thing at a given

\footnotetext{
particular agent. Timothy Williamson's (200o) account of knowledge as evidence would be one such approach.

${ }^{20}$ Notable exponents of this kind of argument include Adler (2002), Hookway (2000), Kelly (2002), and Pojman (1985).

${ }^{21}$ '[W] hat we take to be evidence...' is not meant to imply that we must conceptualise particular considerations as evidence.

${ }^{22}$ For a detailed discussion of this problem, see Reisner (2009).
} 
time that we psychologically can believe is what we do believe, given a particular set of conditions. In this case, we would only have reasons to believe those things that we do or will believe, given a particular circumstance. While this may yield some evidential reasons, in those cases in which our beliefs accord with the evidence, it yields far too few reasons. Agents who are not responsive to evidence as characterised by the favoured theory of evidence have no reasons to be responsive to that evidence, since they psychologically cannot be responsive to them: the possibility of believing against one's reasons is ruled out.

Finally, if we take 'can' as 'can physically', all sorts of beliefs are possible through deviant or at least atypical causal interventions, such as being knocked on the head or as a consequence of being put under hypnosis. In this case, reasons for belief will not be restricted to evidential reasons for belief.

The old style argument yields too few or too many reasons for belief to serve as a successful argument for evidentialism. It has largely been abandoned in favour of a different family arguments for evidentialism, which are termed 'new style' arguments for evidentialism.

\section{NEW STYLE ARGUMENTS FOR EVIDENTIALISM}

New style argument for evidentialism are varied in their precise content, and specific versions have specific objections associated with them. In this section, I shall offer a generic way of understanding new style arguments. In $\mathbb{S}_{4}$, I shall offer a pair of generic arguments for rejecting them. Readers interested in more detailed discussion of specific approaches are encouraged to read the relevant cited works.

New style arguments for evidentialism rely on two basic claims. One is what I shall call the 'conceptual normativity of the mental thesis' (CNMT). ${ }^{23}$ The other is what I shall call 'the alethic

\footnotetext{
${ }^{23}$ Discussion of the normativity of the mental, or of content, make up their own robust area of study. For the
} 
belief orthodoxy thesis' (ABOT).$^{24}$ I shall not be formulating either in a very precise way, as they each stand in for a closely connected family of views rather than a generally agreed upon single formulation.

CNMT is the thesis that reasons for mental states arise from the essential conceptual features of the states themselves. ABOT is the thesis that the relevant essential features of belief are $a$ ) that to believe $p$ is necessarily to take it that $p$ is true $;^{25}$ and $b$ ) that the relevant belief formation, maintenance, and revision mechanisms are responsive to what an individual takes as evidence for the contents of a given belief.

\section{Defending $A B O T$}

CNMT is a datum in new style arguments for evidentialism. Consequently, different versions of the new style arguments vary according to how they defend ABOT. There are two main approaches to doing so.

The first approach may be thought of as an argument from reasoning. ${ }^{26}$ The starting point is an observation that explicit reasoning about what to belief and what to intend are different, at least superficially, from reasoning about other kinds of mental states. Typically, reasoning processes that lead us to form an intention to do something - let us say to intend to boil the cabbage - take the form of reasoning about whether to boil the cabbage, as opposed to whether to intend to boil it. Likewise with belief, the process that leads us to form the belief that kale is healthier than suet takes the form of reasoning about the truth of whether kale is healthier than suet, not whether to

\footnotetext{
argument against something like CNMT, see Speaks (2009). In defence of it, see Whiting (2013). An extensive discussion may be found in Hattiangadi (2007).

${ }^{24}$ I discuss these thesis, and their relation to evidentialism, in Reisner (2013).

${ }^{25}$ Although this does not imply that one must take it to be true under the description 'is true'.

${ }^{26}$ This is exemplified by Hieronymi (2005) and Shah (2003 and 2006). Hieronymi's argument depends on a central load bearing notion of bearing on a question. Taken in isolation from the rest of the paper, her argument for evidentialism is similar to Shah's in conception and structure. Both have their roots in the work of Richard Moran.
} 
form the belief that kale is healthier than suet. On the other hand, we generally do not omit the terms 'wants' or 'wishes' when we are reasoning explicitly about about what to want or what to wish for. $^{27}$

There is a lesson that we are supposed to take from the distinctiveness of belief (and intention) reasoning. It is that the contents of the mental states are that, about which we are reasoning, rather than about the states themselves. The upshot in the case of belief is that we are reasoning about whether a particular content is how the world in fact is. From this we are intended to infer that good reasoning tracks the relation between the truth of a set of premisses and the truth of the conclusion inferred from them. This relation, claim evidentialists, is evidential, either always or most of the time, depending on whether they are strict or slack evidentialists. ${ }^{28}$

A further, substantive step is required to complete the argument. This step is to assign a privileged status to evidentially sensitive, truth directed reasoning about the contents of beliefs. Whatever this status amounts to, it must be enough to warrant making a particular claim about the application of CNMT to beliefs. Roughly, what is required is that when we apply CNMT to the belief that $p$, the belief the $p$ must be sensitive to what one takes to be evidence regarding $p$.

The second approach is to treat ABOT as being analytically entailed by the concept BELIEF. ${ }^{29}$ This analytic approach typically relies on having a functionalist account of beliefs as mental states. ${ }^{30}$ The outputs of belief states are typically understood as dispositions to act, in combination with appropriate desires. The inputs are evidence. Belief-like states which come about not in response to evidence, or perhaps more correctly the appropriate mental analogue of evidence, are

\footnotetext{
${ }^{27}$ In this way, reasoning about wanting or wishing is sometimes labelled as 'non-transparent', whereas reasoning about beliefs and intentions is 'transparent'. Shah (2006) uses the term 'transparency' in a quite different way.

${ }^{28}$ Shah (2006) and Skorupski (2011) suggest that it is always evidential. Adler (2002), although not a proponent of the new style arguments for evidentialism, seems to concur.

${ }^{29}$ Some philosophers might prefer to talk about something's being analytically entailed by the predicate belief.

${ }^{30}$ Skrourpski (2011) is a notable exception.
} 
on this definition not beliefs, even if they otherwise play the same role within an agent's cognitive ecology. ${ }^{31}$ This is what may be called the 'analytic defence' of ABOT, because ABOT is effectively a consequence of how BELIEF is analysed, or perhaps how 'belief' is defined.

4. Why THE NEW STYLE ARGUMENT IS UNSUCCESSFUL: STRICT EVIDENTIALISM AND MANY FIXED POINT AUTO-ALETHIC BELIEFS

Strict evidentialism, recall, is the view that the only normative reasons for a belief are evidence for its contents. It is a demanding view, but it, rather than slack evidentialism, is the one commonly argued for by proponents of the new style argument. Although it is not clear that proponents of the new style argument were aware of this at the time that the argument was developed, they were right to aim for strict evidentialism. Slack evidentialism easily leads to ecumenical evidentialism. This section shows how this is so, and at the same time why the new style arguments for strict evidentialism are also unsuccessful. The argument from auto-alethic beliefs also - not unrelatedly - suggests that permissivism about evidence is correct in the permissivism/non-permissivism debate about the whether a given evidence determines a uniquely correct doxastic state for a given agent. ${ }^{32}$

Auto-alethic beliefs and the many fixed point numbers game

An auto-alethic belief is one that secures its own truth. Familiar examples include the belief that I have a belief and the belief that I exist. The familiar examples are elegant, in part because

\footnotetext{
${ }^{31}$ Nayding (2011) makes this observation. Her discussion of the analytic defence of ABOT was well ahead of its time. The analytic argument itself does not have a definitive statement. Important strands in its development include Stalnaker (2002) and Williams (1973).

${ }^{32}$ See Kelly (2013) and White (2013) for a succinct summary of the permissiveness debate. This question of evidential permissiveness arises briefly in Reisner (2013 \& 2014). See Morton Dahlback (forthcoming) for a more extensive discussion of the many fixed point auto-alethic beliefs and the permissiveness debate. I thank Marc-Kevin Daoust for discussions about this particular issue and about the auto-alethic beliefs in general.
} 
one can know a priori that those beliefs are true. However, it is not a necessary condition on an auto-alethic belief that it can be known to be true a priori. There are interesting cases in which one can have a posteriori knowledge that certain auto-alethic beliefs are, or will be, true in virtue of one's believing them. With respect to arguing against evidentailists, it is perhaps worth examining in particular an argument built on a case with auto-alethic beliefs about the contents of which one can have a posteriori knowledge. This is because at least some evidentialists think that beliefs, the contents of which are knowable a priori fall into a contested class of hard cases not suitable for one's basic normative epistemological theorising. ${ }^{33}$

One such example is the many fixed point numbers game. Here is a simplified version. ${ }^{34}$ You can imagine being attached a brain scanner that can read your beliefs. This brain scanner is in turn attached to a computer with a display. The complete apparatus, the operation of which you understand perfectly, does the following. You are prompted by a message on the display with the question 'What number will appear next on this display?' The scanner will then check to see if you have a well formed belief about what number will appear on the display. A well formed belief is one of the form that an individual real number, $n$, will appear on the screen.

If you have a well formed belief, and if $n>0$, then the number that the computer will display on the screen will be the sum of $1 / 2 n+1$. So, if you believe that the number will be 28 , then the number displayed will be 15 . If you believe that the number will be 15 , it will be 8.5 , and so on. Let us suppose that you have designed the apparatus yourself, and consequentially this is all evident to you.

If you have a well formed belief, and if $n \leq 0$, then the number that will appear on the screen

\footnotetext{
${ }^{33}$ Alder (2002) ch. 1, discusses the grounds for restricting arguments about normative epistemic reasons to more ordinary empirical beliefs. I am uncertain of what he would have thought of this example.

${ }^{34}$ More complete treatments can be found in Reisner (2013 and 2014). A discussion of a single fixed point version of the numbers game may be found in Reisner (2007).
} 
will be the difference of $1 / 2 n-1$. If on the other hand you do not have a well formed belief about what number will appear on the screen, then 16 will appear. There is a one minute delay between the scan time and the display time. If, during that time, your belief about what number will appear on the screen changes, the computer rescans, the clock starts anew, and the formulae concerning what number will appear on the screen are applied to your new belief.

In this scenario, there are three stable beliefs: that 2 will appear on the screen $(1 / 2 \times 2+1)$, that -2 will appear on the screen $(1 / 2 \times-2-1) \cdot{ }^{35}$ Assuming that you neither have an antecedent disposition to form any particular one of these beliefs, nor believe that you have such a disposition, there is no evidence for any particular one of those beliefs. Yet, given the set up of the apparatus, each of the stable beliefs is auto-alethic: your believing it will secure that belief's truth. And because you know how the apparatus works, you also know a posteriori that each of those beliefs auto-alethic.

In this scenario, to believe anything other than one of the two fixed points is to believe something, knowing it to be false. It is epistemically impermissible to believe known falsehoods. It is also impermissible to suspend judgement about what number will appear on the screen, because you know that suspending judgement about what number will appear on the screen will cause the number 16 to appear on the screen. Provided that you are sensitive to the evidence, you will then believe that 16 will appear on the screen, which will then lead you to believe that 9 will appear on the screen, and so on.

The only permissible doxastic states in the many fixed points numbers game are the stable beliefs. It is always epistemically permissible to believe, and to come to believe, an auto-alethic belief. ${ }^{36}$ On the other hand, every other doxastic state is epistemically impermissible, whether a

\footnotetext{
${ }^{35}$ Marc-Kevin Daoust pointed out to me that there is a disjunctive belief that is also stable: that 16 or something else will appear on the screen. Whether this should be included as a third fixed point depends on how one reads the 'well formed' clause. It is not consequential to my argument, and so I have omitted discussion of this third possibility from the discussion. I thank Daniel Star for helpful comments about this issue.

${ }^{36}$ This is intuitively clear. An explanation of why it is always epistemically permissible to believe known auto-alethic
} 
positive belief or a suspension of judgement. The former are foreseeably false and the latter is contrary to the evidence.

So far I have only discussed permissibility. Permissibility is weaker than being a reason. In this case, however, that it is epistemically permissible to have one of the fixed point beliefs entails that it is epistemically required that one have one of the fixed point beliefs. This is the argument:

We should accept the following inference pattern:

1. Necessarily $(\neg a \leftrightarrow b)$

2. Permissible $\neg a$

$\therefore$ 3. Permissible $b$

Let $p$ stand for 'You believe that the number on the screen will be 2, or you believe that the number on the screen will be -2 , or your believe that the number on the screen will by a disjunction of 16 and something else. And nothing more.' Let $q$ stand for 'Your doxastic state is not one of the ones listed in p.' Applying the inference pattern above, we get:
1. Necessarily $(\neg p \leftrightarrow q)$
2. $\neg$ Permissible $(q)$
$\therefore 3 . \neg$ Permissible $\neg p$

Not epistemically permissible not $p$ is equivalent to epistemically required $p$. Requirements are

beliefs is provided in Reisner (2013 and 2014). 
stronger than reasons, ${ }^{37}$ and so there is an epistemic reason - indeed a complete epistemic reason to believe $p$.

This argument refutes strict normative evidentialism, because one has a reason to believe each of the two fixed points, but there is no evidence for either of them. Interestingly, it also provides a prima facie argument for permissivism about total evidence, as the total body of evidence determines only that there are several permissible doxastic states, rather than a single required doxastic state. The many fixed points numbers game is compatible with slack non-ecumenical evidentialism, but as I shall show in $\mathbb{S}_{5}$, it is also suggests a limited form of ecumenical evidentialism.

\section{Rejecting ABOT}

The many fixed points numbers game is consistent with ABOT, if ABOT is understood broadly enough. What it shows is that ABOT and CNMT do not jointly entail strict ecumenical evidentialism.

The argument from auto-alethic beliefs shows that non-heroic versions of the analytic defence of $\mathrm{ABOT}$ are doomed to fail. ${ }^{38}$ Analyses of belief are not intended as mere assertions, but rather as efforts to capture and make precise something central to the concept of a belief. A functionalist account of belief that has evidence, or what is taken to be evidence, alone as the input type for beliefs is trying to capture the essential truth tracking aim of belief. Because bodies of evidence can be permissive, as they are in the many fixed points numbers game, there is sometimes no uniquely determined doxastic state to be in, and suspension of judgement itself ruled out on evidential

\footnotetext{
${ }^{37}$ When we are speaking of normative requirements. I am assuming that evidentialists are treating epistemic requirements as normative requirements. There may be non-normative requirements in non-normative domains, such as the requirements of etiquette. That there is a requirement of etiquette does not entail that there are reasons of etiquette.

${ }^{38}$ By 'non-heroic', I mean analyses that are not treated as being insusceptible to counter-examples or argument. A heroic analysis might resist counter examples and arguments on theoretical grounds.
} 
grounds. ${ }^{39}$ Consequently, an alethically motivated functionalist analysis of belief will require more diverse inputs than evidence, as well as some kind of capacity for spontaneous belief formation in the face of many permissible, but mutually exclusive beliefs.

This leaves open a separate question about whether $\mathrm{ABOT}$ is true at all. This issue arises again in $\mathbb{S}_{5}$, but I would like to suggest that defending ABOT, without assuming something like evidentialism, is difficult. To illustrate this point, it is instructive to consider Hieronmyi's approach to defending evidentialism. ${ }^{40}$

Hieronymi offers a slightly different account of what it is to be a reason to the standard one. According to her, a reason is a consideration that can serve as a premiss in a piece of reasoning. By itself, this offers little restriction on what sort of considerations can be reasons for what sort of mental states. One might reason in unorthodox ways, or just badly. To avoid this problem, the notion of bearing on a question is introduced to identify canonical forms of reasoning for particular sorts of mental states.

When we reason about what to believe in the ordinary way, let us say whether to believe that $p$, the premisses of the reasoning are said to bear on the question: whether $p$. What bears on whether $p$ are considerations concerning the truth of $p$. By way of contrast, reasoning that issues in an intention, say about $\varphi$-ing, has premisses that bear on the question: whether to $\varphi$.

There is an immediate difficulty with this approach to identifying canonical forms of reasoning, which is that the notion of bearing on question is equivocal. Questions, as normally understood, are contents with an interrogative force. The question, whether $p$, has as its contents $p$.

\footnotetext{
${ }^{39}$ It is my view that the many fixed points number game suggests a limited form of direct doxastic voluntarism. See Reisner (2013) for an extend discussion.

${ }^{40}$ See Hieronymi (2005). Hieronymi's position on strict evidentialism is uncommitted. It is accurate to say that she thinks that all reasons of the right kind for belief are those that fall under strict evidentialism, as I have outlined it here. Importantly, given her understanding of what it is to be the right kind of reasons, she shares a similar argumentative burden with those who are clearly strict evidentialists. Whether Hieronymi thinks that wrong kind of reasons are genuine reasons with normative significance in the same sense that the right kind are is unclear.
} 
What bears on $p$ is evidence. The question, whether to $\varphi$, has as its contents $I \varphi \cdot{ }^{41}$ If bearing on a question were univocal, then the premisses in intention reasoning would also be evidential, conflating intention with prediction.

This suggests that bearing on a question in the case of intention reasoning involves assuming some norm about how we answer the question whether to $\varphi$, not what bears on the contents of the question per se. So, it appears that bearing on a question equivocates between bearing on the contents of a question and bearing on the right way to answer the question.

To read Hieronmyi's argument as unequivocal, then we have to understand the question of what bears on whether $p$ as being a demand for what bears on how one ought to answer the question, not what bears on the truth of its contents, otherwise the account of intention is instead an account of self-prediction. Whether one ought to answer a question in a given circumstance is by giving one's best estimate of the truth is far from certain. If I ask a friend about whether the expensive new painting that I have purchased is tasteful, the norms bearing on how to answer the question may be those governing whether the answer will offend me, rather than whether the painting is in fact tasteful.

Reflection on Hieronymi's work brings out nicely the main difficult with defending ABOT in a way that can make it part of a non-question begging argument for strict evidentialism. There are many possible ways to reason about whether $p$ is the case. On one's deathbed, one may reason thus: obliteration is too terribly to contemplate, so I shall be reincarnated. This reasoning relies on a pragmatic premiss, and it is evident that people not uncommonly do reason in just this way. ${ }^{42}$ What actually determines whether $p$ is the case, short of assuming a Panglossian optimism at any rate, are the relevant features or facts that are the truth makers for $p$. What indicates whether $p$ is

\footnotetext{
${ }^{41}$ In the context of first person reasoning, the infinitive form suppresses the subjects. This may easily be seen by considering how one might post the question to one's self: Shall I got to the shops?

${ }^{42}$ McCormick (2015) offers several good examples of these kinds of cases. See Preface and ch. 3.
} 
the case is the evidence for $p$. We are able to reason about how to answer a question, both directly and indirectly, in such a way as to be insensitive or uninterested in both.

What is required, as we may now see, for ABOT is essentially a claim of brute privilege for alethic belief reasoning. Hieronymi's unsuccessful strategy had been to avoid opening up different possible reasoning modalities by focusing on the question, whether $p$, rather than the question whether to believe $p$. And in one form or another, this is the general tactic for establishing ABOT used by proponents of the new style arguments for evidentialism. If the best hope for defending $\mathrm{ABOT}$ is, in effect, just an assertion of privilege for alethic reasoning patterns for belief, it is difficult not to understand the defence of $\mathrm{ABOT}$ as just relying on the conclusion for which it is supposed to be a premiss: that the norms of belief are all alethic norms.

\section{THE CASE(S) FOR PRAGMATIC REASONS FOR BELIEF}

Having rejected the truth-correctness principle and strict non-ecumenical evidentialism, what is left of the truth norm is at best that there are some evidential reasons for belief, whatever other kinds of reasons for belief there also may be. It is important to recognise that this is a significant concession to the possibility that there are pragmatic reasons for belief. ${ }^{43}$ Unless we stipulate CNMT, independently of the truth of $\mathrm{ABOT}$, to rule pragmatic reasons for belief, then the route to rejecting pragmatic reasons for belief is obscure. Stipulating CNMT in this way is question begging, when the matter at issue is whether there are pragmatic reasons for belief. Defenders of something like CNMT could claim that it is a priori, but defenders of pragmatism could make the equally perspicuous claim that it is a priori that the strong stipulative form of CNMT is false.

Philosophers who wish to argue that there are pragmatic reasons for belief can defend either a

\footnotetext{
${ }^{43}$ Steglich-Petersen (2008) offers an important discussion of problems for evidentialism, if evidential reasons are not exhaustive of all reasons.
} 
stronger or a weaker view. The weaker view holds that there are only truth convergent pragmatic reasons for belief (TCR). The stronger version of the view holds that in addition to TCR, there are truth non-convergent pragmatic reasons for belief (TNR). ${ }^{44}$ TCR are those pragmatic reasons that are consistent with the alethic reasons for belief. TNR are those pragmatic reasons that are not consistent with the alethic reasons for belief. There are three main lines of argument positive argument for pragmatic reasons for belief. The first only supports TCR, where as the latter two support TNR as well as TCR.

Pragmatic Reasons for Belief and Leaps of Knowledge

In the example of the many fixed points numbers game, the total evidence, and indeed the total alethic considerations, do not determine which particular belief one is required to believe before one believes it. ${ }^{45}$

In the state in which one has not yet formed one of the stable beliefs, one has a kind of epistemic choice. Whether this choice is voluntaristic in some particular sense, or whether it is a choice only in the sense of being a matter of epistemic openness may be set aside for now. ${ }^{46}$ To see how the choice of what to believe may be affected in a restricted way by pragmatic reasons, we can change the example slightly.

In the new many fixed points numbers game, everything is that same, save that you will be awarded a prize for believing that the number on the screen will be -2. For the sake of argument let us assume that you can do so. It is plausible to think that the prize adds an additional reason to

\footnotetext{
${ }^{44}$ For more discussion of truth convergent and truth non-convergent pragmatic reasons for belief, see Reisner and Van Weelden (2015).

${ }^{45}$ Recall that it does this while treating suspension of judgement as impermissible.

${ }^{46}$ For some reasons why it may be considered a choice in a voluntaristic sense of 'choice', see Reisner (2013). See McHugh (2014) and Paul (2015) for a detailed discussion of the issues. Williams (1973) thinks that there is no sense in which beliefs can be chosen.
} 
believe that the number on the screen will be -2 as opposed to 2. No epistemic reasons or norms are violated if one believes that the number on the screen will be -2 . Because strict evidentialism has failed, it is at least possible that the prize constitutes a reason for belief. As yet, we at least have no argument that it is not.

We can introduce extension of this case. We can imagine that you now believe that the number will be 2, but '2' has not yet appeared on the screen. You learn that you will receive a prize for believing that the number that appears on the screen will be -2. You will be correct in either case, but it is true that at the moment that you learn of the offer, there is evidence that the number on the screen will be 2 and not -2 .

It is difficult to see precisely what the objection would be to switching beliefs. Neither is inconsistent with the truth. Both are consistent with strong alethic reasons (in each case, you know that if you believe that that number will appear on the screen, it will appear, because you believe it will). If strict non-ecumenical evidentialism were true, then there would be an objection. But, as it is not, we can see that there are different kinds of alethic reasons in play. The pragmatic reasons are consistent with ensuring you believe only the truth about what number will appear on the screen and that you will have no false beliefs about it. ${ }^{47}$

Just what sort of argument this is for pragmatic reasons for belief is not entirely clear. It may be understood as an argument from intuition. It may also be understood as a 'why not?' argument. We can assign some sort of positive judgement to forming the belief that you both know will be true and that will win you the prize. If we have rejected strict evidentialism and the truth-correctness principle, it is unclear why a positive evaluation would not provide a reason in this case. At minimum, as long as there is no reason to believe there are no pragmatic reasons for belief, the onus shifts to the would be alethicist to explain why incentives to believe something, when those

\footnotetext{
47 This is example, although now different in form and substance, has its origins in the power of positive thinking example, due to Harman (1999).
} 
incentives are truth convergent, do not constitute or provide reasons for belief themselves.

The Arguments from Agency and Ethics

Discussions about normative reasons for belief commonly focus on epistemic agency in a narrow way that sees it as divorced, or at least isolated from, wider considerations about what it is to be an agent. The thought, roughly, is that something like the truth norm, and specifically something like ABOT, can only carry force if we think about epistemic agency outside the broader context of a life.

One way of bringing this out is to think about our life as agents as being directed towards realising our broad aims. Miriam McCormick has argued that in the context of bringing our aims to fruition, we exercise our agency in a variety of direct and indirect ways both on our actions and on our mental life. ${ }^{48}$ Our prospects for success in carrying out our projects often depend on our having true beliefs, but not always. Sometimes, we are better off with false beliefs that will give us more confidence or that will allow us to lead happier lives.

One of the central steps to seeing beliefs as part of a wider agential tapestry, for which there are many different kinds of reasons for belief and for other mental states, it to reject ABOT. McCormick suggests that there is no principled explanation of why our typical direct reasoning practice of considering the truth of a belief is more important for setting the norms for belief than other less direct belief formation practices over which we have voluntary control. With Pascal, we could imagine going to church voluntarily to cause ourselves to become theists. If epistemic agency is seen in its broad context, then its norms, she argues, should arise from the broad context of reasoning that ultimately has a belief as its outcome, if not as its conclusion.

It is difficult to evaluate McCormick's view in a short space, but even from this brief sketch, its

\footnotetext{
${ }^{48}$ McCormick (2015).
} 
challenge to ABOT should be clear. It is not just that ABOT may be insufficient for use in defence of evidentialism, but in fact the general strategy of appealing to reasoning to defend evidentialist and altheticist views requires a particular and not unchallenged way of dividing the epistemic aspects of our agency from the practical ones. ${ }^{49}$

Ethical arguments for pragmatic reasons for belief are arguments that show pragmatic reasons for belief are essentially entailed or required for our ethical obligations to be satisfied. Although they have been offered independently, these arguments may be used to motivate the argument from agency. They suggest that practical ethical obligations and practical reasons cannot easily be separated from what we have reason to believe.

There are two main strategies for developing the ethical arguments for pragmatic reasons for belief. The first is difficult belief and the second is ethical partiality. In a series of papers and a book, ${ }^{50}$ Berislav Marušić outlines cases of difficult belief. These are cases in which certain ethical practices require us to form beliefs against what we know to be the evidence. These cases are difficult because the reasons for belief that Marušić argues that they provide are non-convergent. He offers many excellent examples, but a particularly vivid one are of wedding vows. ${ }^{51}$ In many wedding vows both partners promise to love and be with each other for the rest of their lives. However, many people who get married are aware that divorce rates in their community are high. We could imagine two social statisticians getting married. They know not only that divorce rates are high, but that they are unlikely to be special exceptions to the behaviours of their peers.

In this social statistician's marriage, to promise to marry one's partner forever is to promise against the evidence. It is a constitutive condition of promising on many accounts that one believe

\footnotetext{
${ }^{49}$ Susanna Rinard (forthcoming) adopts a similar argumentative strategy to McComrick's.

${ }^{50}$ See especially Marušić (2012, 2013, and forthcoming).

51 The main discussion of this example is in Marušić (2012 and forthcoming). A related example is discussed in Marušić (2013). I have changed the details of the case some to fit more easily with the discussion in this chapter.
} 
that one will do as one promises. Yet, what each is promising to do is something against which the social statisticians have strong evidence. Intuitions about the case may vary, but it is at least plausible that each social statistician both has a reason to make the promise and, as a consequence, has a reason to believe that she will stay married to her partner for the remainder of her life.

Sarah Stroud offers an argument from epistemic partiality and friendship. ${ }^{52}$ She argues that it is constitutive of certain kinds of social relations that involve trust and deference that they must be insensitive to evidence about the participants in those relationships. Part of what it is to be someone's friend is, when confronted with evidence of disloyalty or unkindness, to discount the force of that evidence. According to Stroud, this is not because some feature of friendship gives one epistemic reasons - for example that one knows one's friend is trustworthy - to discount the evidence. Rather, being epistemically partial just is part of what it is to be a friend, and thus one has pragmatic reasons for epistemic partiality to the extent that the institution of friendship confers reasons more generally.

Of course, there are arguments to be had about whether any particular ethical view is correct. What is interesting about the structure of Marušićs and Stroud's ethical arguments is that they draw on the way in which certain ethical practices or institutions, such as promise keeping and friendship, constitutively cannot be realised without certain beliefs. Those beliefs may be against the evidence, contingently in the statistician's wedding and essentially for partiality in friendship. The ethical arguments and the argument from agency jointly suggest that at minimum, the picture of a rigidly divided theoretical agential psychology and normative regulatory scheme have no special claim of privilege, either in ethics or in accounts of agency, that entitles philosophers to assume anti-pragmatism as default view about reasons for belief.

\footnotetext{
${ }^{52}$ Stroud (2005). Simon Keller (2004) independently developed arguments in a similar vein.
} 
The No Positive Normative Judgement Argument

The last argument for divergent pragmatic reason for belief is the no positive normative judgement argument (NPNJ). The argument is best understood as the pairing of an intuition with a schema for generating thought experiments. ${ }^{53}$

Let us begin with the thought experiment schema. A mad scientist, evil demon, or some other outside force makes it that case that if you do not believe not $p$, some suitably terrible outcome will ensue. Separately, let us suppose that $p$ is the case, and that all the evidence available to you suggests that $p$ is the case. On this thought experiment schema, there are moral or prudential incentives to believe not $p$. All the alethic reasons weigh in favour of believing $p$, and also in favour of not believing not $p$.

According to some philosophers, this is a case in which there are both evidential and pragmatic reasons for belief, and those two types of reasons conflict. ${ }^{54}$ But this is controversial, and an influential line of evidentialist thinking instead seeks to treat the incentives as providing reasons for something other than beliefs. Some authors claim that moral or prudential incentives for believing not $p$ are reasons to cause yourself to believe not $p \cdot{ }^{55}$ Others claim that they are reasons to desire to believe not $p .{ }^{56}$ In this way, we can assign a positive practical normative judgement to the person who arranges for herself to believe not $p$, even though we assign a negative theoretical normative judgement to her believing not $p$. By 'positive judgement', all that is meant is that it is a consequence of the particular normative theory in question that an agent acts or is in a state that is in accordance with the relevant normative reasons.

\footnotetext{
${ }^{53}$ A version of this argument appears in Reisner (2009). Important related discussions appear in Booth (2014a \& 2014b) and Reisner (2008 \& 2015), and Reisner and Van Weelden (2015).

${ }^{54}$ See Danielsson and Olson (2007) and Reisner (2009) for the 'eyes on the prize' argument in favour of treating the incentives as direct pragmatic reasons for belief.

${ }^{55}$ John Skorupski has articulated this view in some detail in Skorupski (2011).

${ }^{56}$ Notably Parfit (2001).
} 
The pragmatist and the anti-pragmatist are in something of a stalemate with regards to intuitions about the simple form of this schema. The the schema can be complicated to put pressure on anti-pragmatist intuitions.

Let us add to the example three further stipulations. One is that incentive for believing not $p$ is defeated by any actions that qualify as causing yourself to believe not $p$. The second is that you already believe not $p$, so there are no concerns about whether you can believe not $p$. The last is that it is not the case that you desire to believe not $p$.

The anti-pragmatist is in a difficult bind. You believe not $p$, but you have not caused yourself to believe not $p$. At the same time, it is not the case that you desire to believe not $p$. We may also assume that you do not believe $p$. You have not conformed to your epistemic reasons, to your practical reasons, nor to your reasons for desiring. Nonetheless, you have saved the world, but there is no positive normative judgement made by the anti-pragmatic theories of reasons.

One is of course free to claim that the right reaction to NPNJ is to say that the agent is in no way how she ought to be, or cannot be said to have done or thought as she ought to have, or had reasons, to do or think. However, it is difficult to see how such a verdict could be motivated except by someone who is in the grip of an anti-pragmatic theory in the first place. It is odd, and I dare say rather high-minded, to imagine that an agent could be considered completely without normative redemption for being such as to effect great goods and no harms. In $\mathbb{S} 1-4$, I have explained why, at least in the current state of the debate, anti-pragmatism has not established itself as a plausible view either in the form of strict non-ecumenical evidentialism or according to the truth-correcntess principle. Consequently, there is little reason to reject NPNJ as providing important support for pragmatic reasons for belief. 


\section{CONCLUSION}

Philosophical arguments and theories often start as efforts to defend strongly held intuitive convictions. That many philosophers have a pre-theoretical commitment to some for of alethicism is unquestionable. Mere conviction is, of course, no argument; the challenge for alethicists has been to provide a good and non-question begging argument for some version of their view. In this task, they have thus far been unsuccessful.

Alethecist, and especially evidentialist, views have been accepted as defaults in discussions about normative reasons for belief in no small part because many philosophers have an intuition that they are true. Evidentialism has been an attractive position, perhaps in part because popular functionalist accounts of beliefs and traditional divisions between the study of the practical and the theoretical appear in certain lights to be suggestive of the truth norm.

Yet it has become increasingly difficult to see just how the gap between suggestive elements of particular views about the mind or about the general study of norms in philosophy on the one hand, and some philosophers' strongly held evidentialist intuitions on the other, could be bridged by an argument. The old style arguments show little promise, and they have largely been abandoned. The new style arguments, as far as can be seen at present, require a premiss somewhere that asserts that the alethic aspect of belief's role in our cognitive economy is privileged with respect to CNMT. Yet this premiss appears rather a lot like the intuitive claim that is ultimately being argued for: that truth is what we should be focused on when we think about reasons for belief. At best, new style arguments belong to a kind of evidential's Summa Theologica, when what is need is a Summa Contra Gentiles.

Opening up the possibility of pragmatic reasons for belief is not the same, of course, as claiming that there are pragmatic reasons for belief. As has been discussed in this chapter, positive arguments for pragmatic reasons for have various sources of support. Whether any proves, or could prove, dispositive remains to be seen. Given, however, that pragmatic reasons for belief at 
minimum seem possible given the current state of our understanding, it may be time to shift the default position to assuming that they exist in those cases where intuition suggests it is so. 


\section{Works Cited}

Adler, J (2002). Belief's Own Ethics. New York: Bradford Books.

Barcan-Marcus, R. (1990). Some revisionary proposals about belief and believing. Philosophical and Phenomenological Research 50, 133-153.

Booth, A. (2014a) Two reasons why epistemic reasons are not object-given reasons. Philosophy and Phenomenological Research 89: 1-14.

Booth, A. (2014b) Epistemic ought is a commensurable ought. The European Journal of Philosophy 22: 529-539.

Dahlback, M. (forthcoming) Infinitely permissive. Erkenntnis.

Dancy, J. (200o). Practical Reality. Oxford: Oxford University Press.

Danielsson, S. and Olson, J. (2007). Brentano and buck-passers. Mind, 116, 511-522.

Hattiangadi, A. (2007). Oughts and Thoughts: Rule Following and the Normativity of Content. Oxford: Oxford University Press.

Harman, G. (1999). Rationality. In Reasoning, Meaning, and Mind (pp. 9-45). Oxford: Clarendon Press.

Hieronymi, P. (2005). The wrong kind of reason. The Journal of Philosophy, 102: 437-457.

Hookway, C. (2000). Epistemic norms and theoretical deliberation. In J. Dancy (Ed.) Normativity (pp. 6o-77). Oxford: Blackwell Publishers Ltd.

Kelly, T. (2002). The rationality of belief and some other propositional attitudes. Journal of Philosophical Research, 110, 163-196. 
Kelly, T. (2013). Evidence can be permissive. In M. Steup \& J. Turri (eds), Contemporary Debates in Epistemology. London: Blackwell. 312.

Marušić, B. (2012). Belief and difficult action. Philosophers' Imprint 12: 1-30.

Marušić, B. (2013). Promising against the evidence. Ethics 123: 292-327.

Marušić, B. (forthcoming). Evidence and Agency: Norms of Belief for Promising and Resolving. Oxford: Oxford University Press.

McHugh, C. (2014). Exercising doxastic freedom. Philosophy and Phenomenological Research 88: 1-37.

McCormick, M. (2015). Believing against the evidence: agency and the ethics of belief. New York: Routledge.

Mitova, V. (MS). Believable Evidence.

Parfit, D. (2001). Reasons and rationality. In D. Egonsson, J. Josefsson, B. Petersson, and T. Rønnow-Rasmussen (Eds.) Exploring Practical Rationality (pp. 17-39). Aldershot: Ashgate.

Paul, S. (2015). Doxastic self-control. American Philosophical Quarterly 52: 145-158.

Pojman, L. (1985). Believing and willing. Canadian Journal of Philosophy 15: 37-56.

Reisner, A. (2007). Evidentialism and the Numbers Game. Theoria 73 (4):304-316.

Reisner, A. (2008). Weighing pragmatic and evidential reasons for belief. Philosophical Studies $138(1): 17-27$.

Reisner, A. (2009). The possibility of pragmatic reasons for belief and the wrong kind of reasons problem. Philosophical Studies 145 (2):257 - 272.

Reisner, A. (2013). Leaps of knowledge. In T. Chan (Ed) The Aim of Belief. 
Oxford: Oxford University Press: 168-183.

Reisner, A. (2015). Normative conflicts and the structure of normativity. In I. Hirose and A. Reisner (Eds) Weighing and Reasoning: Themes from the Work of John Broome. Oxford: Oxford University Press: 189-206.

Reisner, A. and Van Weelden, J. (forthcoming). Moral reasons for moral beliefs: a puzzle for moral testimony pessimism. Logos and Episteme.

Rinard, S. (2015). No exception for belief. Philosophy and Phenomenological Research 9o (2).

Shah, N. (2003). How truth governs belief. Philosophical Review 112 (4):447-482.

Shah, N. (2006). A new argument for evidentialism. Philosophical Quarterly 56 (225): 481-498.

Skorupski, J. (2011). The Domain of Reasons. Oxford: Oxford University Press.

Speaks, J. (2009). The normativity of content and the Frege point. The European Journal of Philosophy 17: 405-415.

Steglich-Petersen, A. (2008). Does doxastic transparency support evidentialism? Dialectica $62(4): 541-547$.

Stich, S. (1990). The Fragmentation of Reason: Preface to a Pragmatic Theory of Cognitive Evaluation. Cambridge, Bradford Books / MIT Press.

Stalnaker, R. (2002). Epistemic Consequentialism. Aristotelian Society Supplemental Volume 76: 53-168.

Stroud, S. (2006). Epistemic partiality and friendship. Ethics 161: 498-594.

Wedgwood, R. (2002). The aim of belief. Philosophical Perspectives 16: 267-97.

White, R. (2013). Evidence cannot be permissive. In M. Steup \& J. Turri (eds), 
Contemporary Debates in Epistemology. London: Blackwell. 312.

Whiting, Daniel (2013). Nothing but the truth: on the norms and aims of belief. In Timothy Chan

(ed), The Aim of Belief. Oxford: Oxford University Press. 184-203.

Williams, B. (1973). Deciding to believe. In Problems of the Self (pp. 136-151).

Cambridge: Cambridge University Press.

Williamson, T. (2000). Knowledge and its Limits. Oxford: Oxford University Press. 